\title{
THERMODYNAMIC EVALUATION OF ORGANIC RANKINE CYCLE CONFIGURATIONS TO INCREASE ENERGY AND EXERGY EFFICIENCY OF BIOGAS COGENERATION POWER PLANT
}

\author{
Ahmet Serhan Hergul ${ }^{1}$, Muharrem Eyidogan', Yusuf Cay², Fatma Canka Kilic ${ }^{1 *}$ \\ ${ }^{1 * K o c a e l i ~ U n i v e r s i t y, ~ T e c h n o l o g y ~ F a c u l t y, ~ D e p a r t m e n t ~ o f ~ E n e r g y ~ S y s t e m s ~ E n g i n e e r i n g, ~}$ \\ Umuttepe Campus, 41001, Kocaeli, Turkey; \\ ${ }^{2}$ Sakarya University of Applied Sciences, Technology Faculty, Mechanical Engineering Department, \\ Esentepe Campus, Serdivan, Sakarya, Turkey;
}

*Corresponding Author Fatma Canka Kilic, e-mail: fatmacanka@ hotmail.com;

Received May 2021; Accepted June 2021; Published August 2021;

DOI: https://doi.org/10.31407/ijees11.406

\begin{abstract}
Organic Rankine Cycle (ORC) is widely used in electricity generation from low temperature waste heat sources. This study introduces the analysis of the biogas cogeneration plant run by internal combustion engines of different power scales. Taking into consideration the variable exhaust temperatures of the engines of the biogas plant operating at asymmetric power and the thermal capacities of the high temperature and low temperature circuits, analyzes and optimizations were realized by considering different fluids and boundary conditions for different cycle types at variable temperatures. To increase the overall efficiency of the plant and to recover the thermal energy thrown into the atmosphere, different fluids in different cycle types have been examined. To designate the working conditions of the proposed system, the energy production and internal consumption data of a working biogas power plant were investigated. Calculations were executed by taking consideration of the long-term recorded gas production data and the corresponding electrical power, electrical efficiency values, thermal production, waste feeding and preheating needs, and environmental conditions. The effects of different cycles on the total energy and exergy efficiencies of the plant were analyzed.
\end{abstract}

Keywords: Organic Rankine Cycle (ORC), a biogas power plant, energy, exergy efficiency, waste heat recovery. 